Review

\title{
Sex differences in ventricular arrhythmia: epidemiology, pathophysiology and catheter ablation
}

\author{
Philipp Krisai ${ }^{1}$, Ghassen Cheniti ${ }^{1}$, Takamitsu Takagi ${ }^{1}$, Tsukasa Kamakura ${ }^{1}$, \\ Elodie Surget $^{1}$, Clémentine André ${ }^{1}$, Josselin Duchateau ${ }^{1}$, Thomas Pambrun ${ }^{1}$, \\ Nicolas Derval ${ }^{1}$, Frédéric Sacher ${ }^{1}$, Pierre Jaïs ${ }^{1}$, Michel Haïssaguerre ${ }^{1}$, \\ Mélèze Hocini ${ }^{1, *}$ \\ ${ }^{1}$ Electrophysiology and Ablation Unit and LIRYC, 33600 CHU de Bordeaux, France \\ *Correspondence: meleze.hocini@chu-bordeaux.fr (Mélèze Hocini) \\ Academic Editors: Bernard Belhassen and Petr Ostadal \\ Submitted: 13 September 2021 Revised: 2 November 2021 Accepted: 10 November 2021 Published: 14 January 2022
}

\begin{abstract}
Evidence on sex differences in the pathophysiology and interventional treatment of ventricular arrhythmia in ischemic (ICM) or nonischemic cardiomyopathies (NICM) is limited. However, women have different etiologies and types of structural heart disease due to sex differences in genetics, proteomics and sex hormones. These differences may influence ventricular electrophysiological parameters and may require different treatment strategies. Considering that women were consistently under-represented in all randomized-controlled trials on VT ablation, the applicability of the study results to female patients is not known. In this article, we review the current knowledge and gaps in evidence about sex differences in the epidemiology, pathophysiology and catheter ablation in patients with ventricular arrhythmias.
\end{abstract}

Keywords: Ventricular arrhythmia; Ventricular tachycardia; Catheter ablation; Sex difference

\section{Introduction}

Sex differences in ventricular arrhythmia (VA) are well established for inherited channelopathies including the Long-QT syndrome, Brugada syndrome and catecholaminergic polymorphic ventricular tachycardia. Considerable less is known about sex differences in the pathophysiology and interventional treatment of (VA) in ischemic (ICM) or non-ischemic cardiomyopathies (NICM). In this article, we review the current knowledge and gaps in evidence about sex differences in the epidemiology, pathophysiology and catheter ablation in these patients.

\section{Epidemiology}

Epidemiological sex differences in ICM and NICM are well recognized. In the United States, men have a higher prevalence of ICM compared to women with a ratio of about 1.34 to 1.00 [1,2]. Women generally have a lower extent of obstructive coronary artery disease, despite a higher burden of comorbidities and a higher age at presentation [3-6]. In women, microvascular coronary dysfunction is a more frequent cause of ICM, compared to a higher prevalence of epicardial obstructive coronary artery disease in men [7-9]. In NICM, sex differences depend strongly on the underlying etiology [10]. Overall, men also prevail with a ratio of 1.27 to 1.00 over women [1]. More specifically, dilated cardiomyopathy has a male to female ratio of 1.44-3.41 to 1.00 [11-14], and hypertrophic cardiomyopathy of 1.70 to $1.00[15]$.
Fewer studies have investigated sex differences in patients with VA and structural heart disease that undergo catheter ablation. Baldinger et al. [16] analyzed 948 consecutive patients undergoing 1314 catheter ablations for sustained monomorphic ventricular tachycardia (VT) over a span of 10 years. Of those 948 patients, 486 patients had ICM with only $9 \%$ of them being female and 301 patients had NICM with $22 \%$ of them being female. Compared to men, women were younger at the time of ablation both with ICM (63 vs 68 years, $p=0.05)$ and NICM (53 vs 59 years, $p=0.026)$. Despite their younger age, they had similar disease severity and outcomes compared to men [16]. Nakagawa et al. [17] analyzed patients undergoing catheter ablation according to their VT location. They found that more women than men presented with right ventricular outflow tract (RVOT) - VT, with a male to female ratio of 0.49 to 1.00 (153 vs 311 patients). In contrast, more male than female patients presented with left ventricular-VT with a male to female ratio of 3.37 to 1.00 ( 175 vs 52 patients). The authors found a more equal sex distribution for left ventricular outflow tract (LVOT)-VT with a ratio of 1.38 to 1.00 (33 vs 24 patients) [17]. Tanaka et al. [18] investigated 625 consecutive patients with symptomatic, drug resistant idiopathic VA undergoing catheter ablation, of whom 310 $(49.6 \%)$ were women. While women and men were distributed equally overall, they again showed that RVOT-VA were more frequent in women compared to men with a male to female ratio of 0.68 to 1.00 . LVOT-VA were more fre- 
quent in men with a male to female ratio of 1.37 to 1.00 . Overall, catheter ablation outcomes were similar and sex was not a predictor for ablation success in multivariate analyses [18].

The female underrepresentation in catheter ablation for VT in ICM might be due to different referral rates between sexes for invasive cardiac procedures [19]. However, women may also have a lower incidence of monomorphic VT in the setting of ICM, though prior data on this are scarce and would not be expected to fully explain the large difference in the number of catheter ablations performed between male and female patients.

\section{Pathophysiology}

\subsection{Genetics, proteomics and metabolomics}

The investigation of pathophysiological sex differences on a genetic or cellular level in ICM and NICM in humans is mainly limited by the number of available tissue samples. In healthy individuals, differences in gene expression are usually due to X-and Y-linked genes. Mechanisms that regulate sexual dimorphisms seem to be tissue-specific in the heart [20]. For example, genes encoding ion-channels and transporter subunits show reduced expressions of several potassium channel subunits, connexin43 and phospholamban in non-diseased female heart explants and an isoform switch in $\mathrm{Na}^{+} / \mathrm{K}^{+}$-ATPase compared to male hearts [21]. However, these differences might be attenuated in diseased hearts.

In a study of 70 men and 32 women with dilated cardiomyopathy and end-stage heart failure, $>1800$ genes were found to be differently expressed between sexes. Again, the majority of them was expressed on sex chromosomes. The biological processes related to these genes were mainly involved in ion transport activity, especially potassium and sodium channels, and G-protein coupled receptor signaling pathways [22]. These mechanisms lead to recognized sex differences: Potassium channel mutations are well known in long QT syndrome, a disease with known sex differences. Also, sex specific expressions of ventricular potassium currents cause differences in cardiac repolarization by lengthening of the action potential duration $[23,24]$. Cardiac sodium channel abnormalities are associated with sudden cardiac death in women [25]. G-protein coupled receptor signaling pathways are involved in the regulation of cardiac inotropy and lusitropy [26]. These findings were corroborated by sex differences in a comprehensive analysis by Li et al. [27]: The authors investigated the transcriptome in patients with dilated cardiomyopathy and new-onset heart failure. They showed sex differences in mitochondrial oxidoreductase reactions and other mitochondrial substrates as well as upregulated nitric oxide synthase inhibitors and elevated trimethylamine $\mathrm{N}$-oxide (TMAO) in males [27]. These differences in proteomics and metabolomics may explain different outcomes in structural heart diseases in men and women, as the pathways are involved in atherosclerosis, recovery after myocardial infarction and development of heart failure [28-31]. Though not proven, it is conceivable that these sex differences in ICM and NICM may also translate into sex differences in VA mechanisms.

\subsection{Sex hormones}

Sex hormones are thought to account for a large portion of sex differences in arrhythmia incidence and outcome. While the presence of estradiol receptors in cardiac tissue is known since over 40 years [32], their specific effects-especially in cardiomyopathies-are not yet fully understood.

Several experimental animal studies investigated the effects of estradiol on ventricular electrophysiology. Hara et al. [33] studied the effects of gonadal steroids on the cardiac action potential in rabbits. Estradiol-treated study animals had a significantly longer action potential duration and significantly more early afterdepolarizations, both of which are known to increase the likelihood of VA [33]. In dogs, cisapride in the presence of 17 beta-estradiol led to a greater increase of ventricular repolarization, a higher incidence of early afterdepolarizations and a subsequently higher rate of Torsades de Pointes [34]. In guinea pigs, James et al. [35] showed varying L-type Calcium currents at different time points of the estrus cycle. These findings might have translational implications to humans, as guinea pigs have a conventional estrus cycle similar to humans. These experimental findings support the role of estradiol in different VA risks between men and women and suggest a dynamic VA risk at different time points in the menstrual cycle.

Data on the influence of sex hormones on VA in humans consists mainly of observational cohort studies. In a cohort of 20 women with premature ventricular complexes (PVCs) and a control group of 18 healthy women, the number of PVCs in the menstruation period was 210 beats/day and decreased to 86 beats/day in the ovulation period ( $p<$ $0.05)$. The average heart rate in the menstruation period was $81.4 \pm 10$ beats/min and increased significantly to $84.6 \pm$ 8 beats/min in the ovulation period. There were no differences in cardiac repolarization parameters in the menstruation and ovulation periods between the study and control groups. However, when the authors compared the menstruation and the ovulation periods within subjects, J-Tpeak interval, which reflects early repolarization, was shorter in the ovulation period $(193 \pm 27.7 \mathrm{~ms}$ and $201.1 \pm 28.6 \mathrm{~ms}$, respectively; $p<0.05$ ) [36]. Further evidence of different arrhythmia risk along the estrus cycle stems from several case reports on paroxysmal VT during pregnancy $[37,38]$. Brodsky et al. [39] reviewed reports on 26 pregnant women with VT, most of them without known structural heart disease. The VTs responded well to Beta-Blocker therapy and in $24(92.3 \%)$ patients no more arrhythmia were recorded after delivery. In contrast, in a cohort of 44 pregnant women with implanted ICDs for ventricular fibrillation and long- 


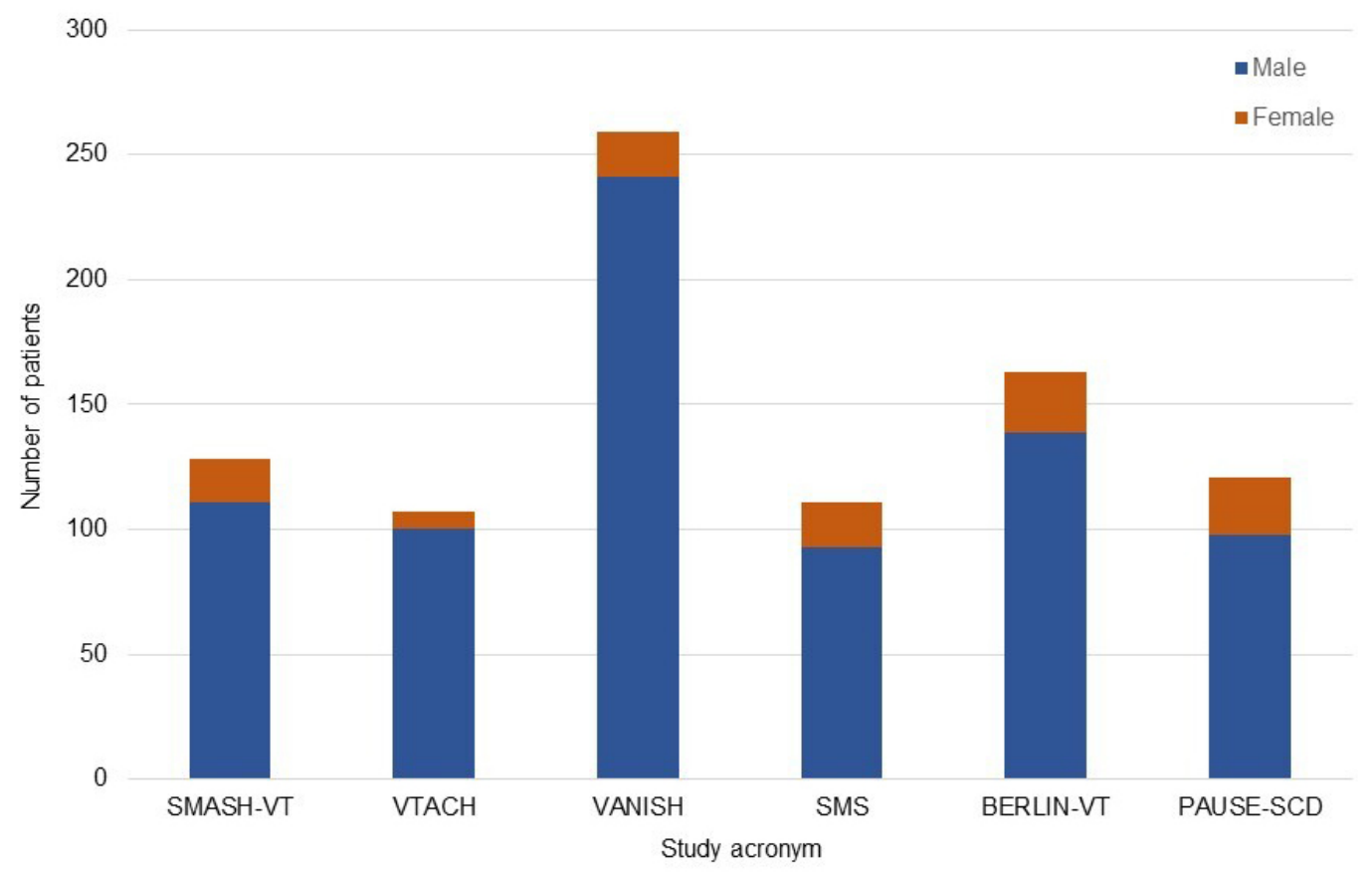

Fig. 1. Sex distribution in randomized-controlled trial investigating catheter ablation for ventricular tachycardia.

QT syndrome, no increased VT rate was found during pregnancy or around labour [40]. Marchlinski et al. [41] investigated sex-specific triggers for RVOT-VT in 34 women and 13 men. In women, triggers depended on different hormonal states, including premenstrual, gestational, perimenopausal time points and the intake of birth control pills. In $20(59 \%)$ of them hormonal states were the most common triggers and in $14(41 \%)$ of them the only one. More support on the importance of female sex hormones on VA was actually found in men. The level of estradiol, but not testosterone, in male patients with outflow-tract VA was shown to be significantly lower compared to male

controls $(p<0.05)$ and a significant negative correlation was observed between the number of PVCs and the level of estradiol [42].

\subsection{Electrophysiological parameters}

Studies to investigate scar patterns, electrograms and VT circuits usually underrepresent women by a ratio of 1:4 to men. Thus, sex specific analyses are often precluded $[43,44]$. Moreover, only few studies investigated electrophysiological sex differences in patients with ICM or NICM. In an observational cohort study, Buxton et al. [45] reported a lower rate of inducible VT in female ICM patients compared to male. However, in their overall cohort of 1721 patients, only $14(0.8 \%)$ were female and in the 549 inducible patients, only $9(1.6 \%)$ were female [45]. Kuo et al. [46] analyzed 160 patients with NICM of whom $26(16.3 \%)$ were female. The investigators compared endocardial uni- and bipolar and epicardial bipolar voltages, but did not find any significant differences. Similarly, they did not find sex differences in scar extent, distribution or transmurality based on cardiac MRI studies [46]. However, their analyses might have been limited by the small group of female patients. Yang et al. [47] analyzed 93 patients with idiopathic RVOT-VT of whom 63 (67.7\%) were female: women had a lower RV voltage $(3.0 \pm 0.7 \mathrm{mV}$ vs 3.7 $\pm 0.9 \mathrm{mV}, p=0.03)$ and about four times larger low voltage zones on the RVOT free wall compared to men $(27.0 \%$ vs $6.7 \%, p=0.02$ ) [47]. In a different population of 70 patients with arrhythmogenic right ventricular dysplasia-34 $(48.6 \%)$ of them being female - men had a larger extent of epicardial RV unipolar low-voltage zones and larger endoand epicardial zones of late potentials [48]. In 83 patients with idiopatic VF, 44 (53\%) of them being female, Purkinje related ectopics triggering VF were differently distributed between sexes. In women, these ectopics originated more commonly from the left or both ventricles, while in men, they originated mainly from the right ventricle [49].

Based on the paucity of data for sex differences in electrophysiological properties in structural heart disease, it is difficult to draw conclusions that can be generalized to larger patient populations. Regarding the definition of lowvoltage zones, more research is needed to assess if current voltage cut-offs are similarly applicable to men and women, considering that women accounted only for $8-25 \%$ in the original studies defining the cut-offs [50-52]. 

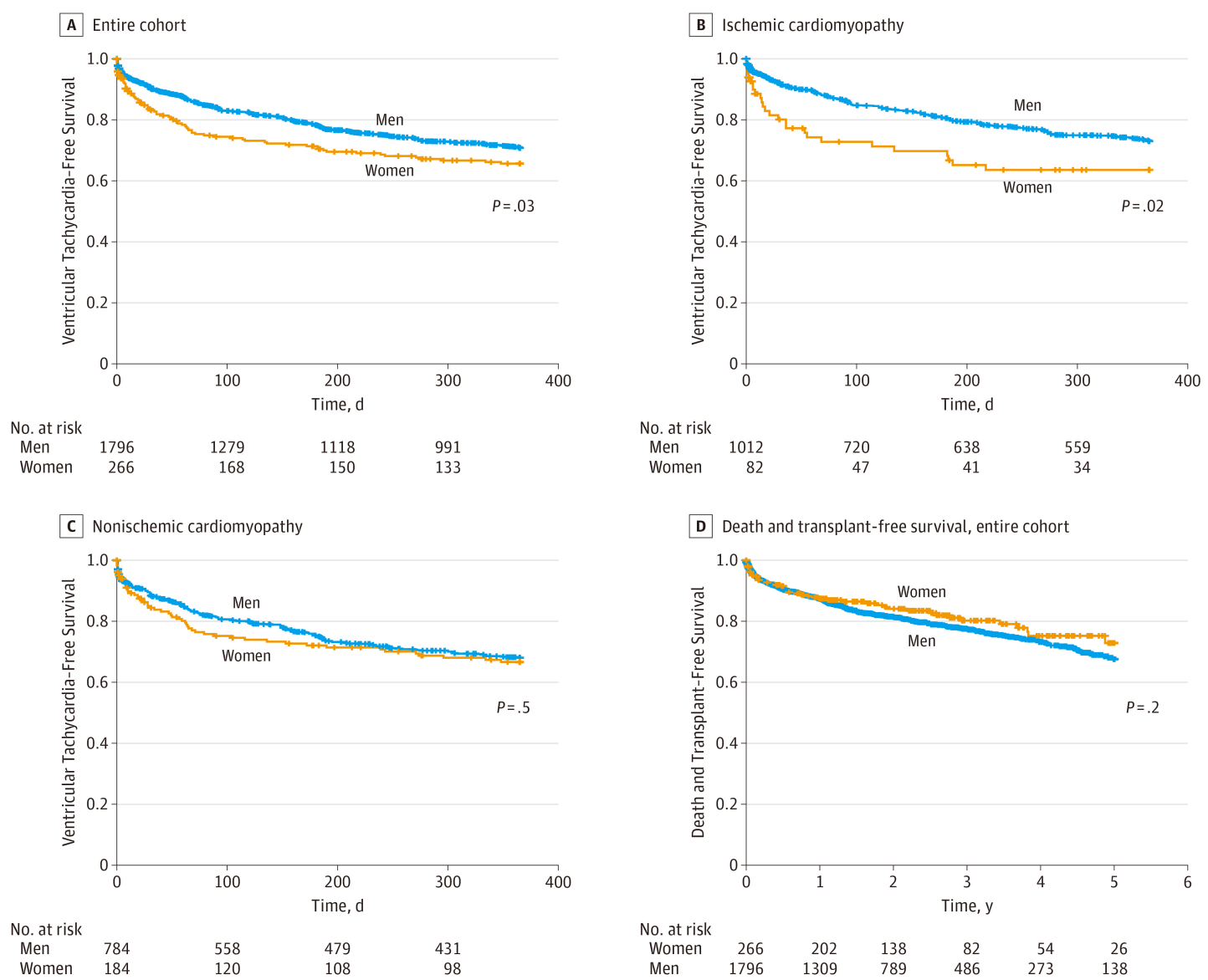

Fig. 2. Ventricular tachycardia-free and transplant-free survivals by sex. (A) Women had worse 1-year ventricular tachycardiafree survival than men following ablation $(\log$-rank $p=0.03)$. (B) Women with ischemic cardiomyopathy had worse 1-year ventricular tachycardia-free survival than men with ischemic cardiomyopathy following ablation (log-rank $p=0.03$ ). (C) Women and men with nonischemic cardiomyopathy had similar 1-year ventricular tachycardia-free survival following ablation $(\log -\operatorname{rank} p=0.55)$. (D) Women and men had similar long-term survival free of death and heart transplant (log-rank $p=0.24)$. Adapted from Frankel et al. [69] with permission.

\section{Catheter ablation}

\subsection{Randomized trials}

Women were underrepresented in most of the major randomized controlled trials that investigated the outcome of catheter ablation for VA and subsequently influenced guideline recommendations (Fig. 1). The SMASH-VT (Substrate Mapping and Ablation in Sinus Rhythm to Halt Ventricular Tachycardia) trial enrolled 128 patients with ICM and investigated whether prophylactic radiofrequency catheter ablation of ventricular substrate would reduce the incidence of ICD therapy. Of those, only 17 (13.3\%) were women [53]. The VTACH (Ventricular Tachycardia Ablation in Coronary Heart Disease) trial enrolled in total 107 patients with stable VT in the setting of ICM, of whom only $7(6.5 \%)$ were female, and tested if catheter ablation for VT before implantation of an ICD conveys a potential benefit [54]. Of the 111 ICM

patients enrolled in the SMS (Substrate Modification Study) trial investigating the effect of prophylactic catheter abla- tion of arrhythmogenic ventricular substrate on VA recurrence, $18(16.2 \%)$ were female [55]. In the VANISH (Ventricular Tachycardia Ablation versus Escalation of Antiarrhythmic Drugs) trial, that compared VT catheter ablation versus escalated antiarrhythmic drugs in ICM patients, 18 (6.9\%) out of 259 patients were women [56]. Similarly, the prematurely terminated BERLIN-VT (Preventive Ablation of Ventricular Tachycardia in Patients With Myocardial Infarction) study enrolled only 24 (14.7\%) female patients out of 163 patients with ICM [57]. These small numbers of enrolled women preclude any meaningful subgroup analyses to investigate the efficacy and safety in female patients with ischemic cardiomyopathy. Moreover, they question the broad applicability of the trial findings to female patients. The recently presented, but not yet published, PAUSE-SCD (Pan-Asia United States PrEvention of Sudden Cardiac Death Catheter Ablation) trial (NCT02848781) investigated catheter ablation versus conventional medical therapy in patients with either ICM or NICM, monomorphic 

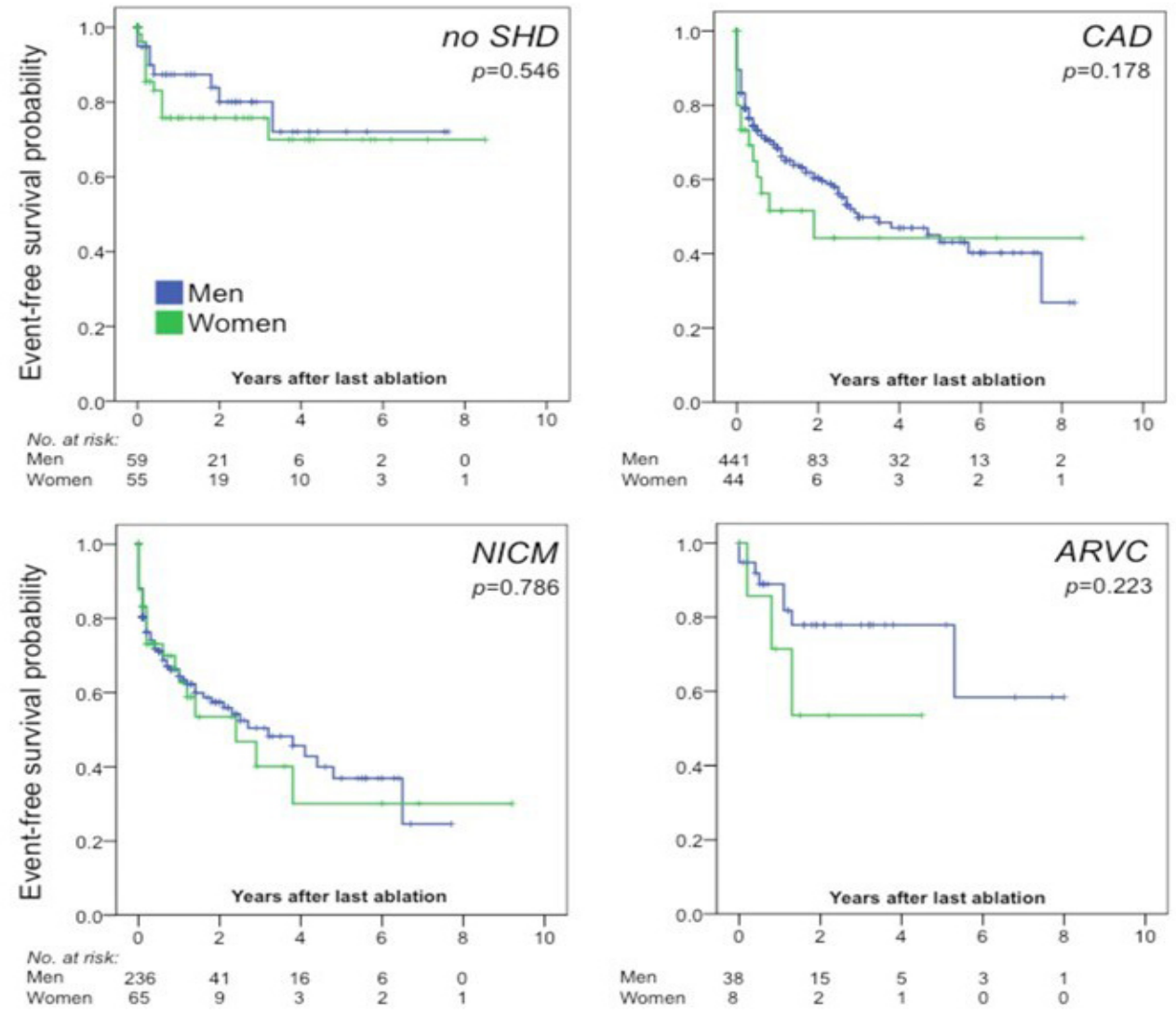

Fig. 3. Comparison of women and men undergoing catheter ablation for sustained monomorphic ventricular tachycardia in different subgroups. Estimated recurrence free survival at 1 year was $87 \pm 5 \%$ for men and $76 \pm 6 \%$ for women without SHD, 70 $\pm 3 \%$ for men and $52 \pm 10 \%$ for women with CAD, $66 \pm 4 \%$ for men and $63 \pm 8 \%$ for women with NICM, and $89 \pm 5 \%$ for men and $71 \pm 17 \%$ for women with ARVC. ARVC, arrhythmogenic right ventricular cardiomyopathy; CAD, coronary artery disease; NICM, nonischemic cardiomyopathy; SHD, structural heart disease. Adapted from Baldinger et al. [16] with permission.

VT and an indication for ICD. The trial randomized 121 patients, of whom 23 (19.0\%) were female, and met its primary composite endpoint of VT recurrence, cardiovascular rehospitalization and death. Importantly the investigators performed subgroup analyses and showed a significant interaction for sex, with less benefit in female compared to male patients.

Based on the female under-representation in randomized VT ablation trials, their results may not be fully applicable to women $[58,59]$. As shown in the subgroup analysis of the PAUSE-SCD trial, women may confer no or less benefit from ablation compared to men, though these results should not be over-interpreted as they are based on small sample sizes.

\subsection{Ablation strategies}

VT ablation approaches based on activation and entrainment mapping should be equally effective in female and male patients as each individual VT is delineated. This may, however, not hold true for purely substrate based abla- tion approaches during sinus rhythm due to sex differences in scar and isthmus distribution. We therefore reviewed sex distribution in the pivotal studies that tested these ablation strategies. Unfortunately, similarly to the randomized controlled trials on VT ablation and cardiovascular outcomes, women were markedly underrepresented in studies on substrate based ablation strategies. A linear ablation approach within the scar, guided by pacemapping, was investigated in a ICM and NICM population with 1 out of 4 patients being female [60]. Similarly, scar dechanneling in NICM was tested in a population including $18 \%$ women [61]. Endo-epicardial scar homogenization approaches in ICM included 19\% women in the initial study [62]. Scar core isolation was tested in the initial study in ICM and NICM with only $5 \%$ being female [63]. The elimination of local abnormal ventricular activities in ICM and NICM was tested in a population with a female proportion of $10 \%$ [64]. Studies investigating the ablation of late potentials included 8,6 and $13 \%$ of female patients [65-67]. Ablation based on isochronal late activation maps ICM and NICM 
was tested in a population with $15 \%$ female patients [68].

Similarly to the randomized trials mentioned above, these small proportions of female participants do not allow sex specific analyses of these ablation approaches and can not ascertain similar outcomes inbetween sexes.

\subsection{Outcomes and complications}

As women were generally underrepresented in the above mentioned trials and studies, registry data may be more informative on outcomes and complications of VT ablation in females compared to males.

In a report from the International Ventricular Tachycardia Ablation Center Collaborative Group Study, women had significantly higher rates of VT recurrence in the year following ablation than men (30.5\% vs $25.3 \%)$ despite being younger, having a higher left ventricular ejection fraction and fewer medical comorbidities (Fig. 2, Ref. [69]). Again only 262 (12.7\%) out of 2062 patients with structural cardiomyopathy were women [69]. Hosseini et al. [70] analyzed $>500.000$ performed ablations, including also atrial ablations, and found female sex as an independent predictor for complications. In contrast, Baldinger et al. [16] did not find differences in success and complication rates between female and male patients in patients with and without structural heart disease (Fig. 3, Ref. [16]). In a cohort with both ICM and NICM reported by Santangeli et al. [71], sex was not a predictor for periprocedural acute hemodynamic decompensation after VT ablation. However, also in this study only $12 \%$ out of 193 patients were female.

Taken together, some but not all observational studies point to an inferior outcome and higher complication rate in female patients compared to males. These differences might be related to the investigated study populations.

\section{Conclusions}

Women have different etiology and distribution of structural heart disease compared to men. These differences span from genetics, proteomics to sex hormones and may influence ventricular electrophysiological parameters. As women were considerably under-represented in all randomized-controlled trials on VT ablation, the applicability of the study results to female patients is not known. Future studies on catheter ablation need to increase female recruitment in order to address this lack of knowledge that is important to half of the planet's population.

\section{Author contributions}

$\mathrm{PK}, \mathrm{GC}, \mathrm{TT}, \mathrm{TK}$ and $\mathrm{MH}$ - structured and organized the review; PK, TT and TK-revised the literature; PKsynthesized the study data; $\mathrm{PK}$ and $\mathrm{MH}$ — wrote the original draft of this paper; PK, ES and CA - updated the review by analyzing prior data; GC, TT, TK, ES, CA, JD, TP, ND, FS, $\mathrm{PJ}$ and $\mathrm{MH}$ - revised and edited the original draft of this paper; $\mathrm{MH}$ - supervised the entire work as senior author. All authors have read and approved the submitted version.

\section{Ethics approval and consent to participate}

Not applicable.

\section{Acknowledgment}

We thank Patrick Badertscher for his assistance in editing the manuscript.

\section{Funding}

PK is supported by the University of Basel, the MachGaensslen foundation and the Bangerter-Rhyner foundation (Bangerther Rhyner: 8472/HEG-DSV; University of Basel: 3MS1039; Mach Gaensslen: no number).

\section{Conflict of interest}

The authors declare no conflict of interest.

\section{References}

[1] Roth GA, Mensah GA, Johnson CO, Addolorato G, Ammirati E, Baddour LM, et al. Global burden of cardiovascular diseases and risk factors, 1990-2019: update from the GBD 2019 Study. Journal of the American College of Cardiology. 2020; 76: 29823021.

[2] Virani SS, Alonso A, Aparicio HJ, Benjamin EJ, Bittencourt MS, Callaway CW, et al. Heart disease and stroke statistics-2021 update: a report from the American Heart Association. Circulation. 2021; 143: e254-e743.

[3] Reynolds HR, Shaw LJ, Min JK, Spertus JA, Chaitman BR, Berman DS, et al. Association of sex with severity of coronary artery disease, ischemia, and symptom burden in patients with moderate or severe ischemia: secondary analysis of the ISCHEMIA randomized clinical trial. JAMA Cardiology. 2020; 5: 773-786.

[4] Tamis-Holland JE, Lu J, Korytkowski M, Magee M, Rogers WJ, Lopes N, et al. Sex differences in presentation and outcome among patients with type 2 diabetes and coronary artery disease treated with contemporary medical therapy with or without prompt revascularization: a report from the BARI 2D Trial (Bypass Angioplasty Revascularization Investigation 2 Diabetes). Journal of the American College of Cardiology. 2013; 61: 17671776.

[5] Acharjee S, Teo KK, Jacobs AK, Hartigan PM, Barn K, Gosselin $\mathrm{G}$, et al. Optimal medical therapy with or without percutaneous coronary intervention in women with stable coronary disease: a pre-specified subset analysis of the Clinical Outcomes Utilizing Revascularization and Aggressive druG Evaluation (COURAGE) trial. American Heart Journal. 2016; 173 : 108-117.

[6] Davis KB, Chaitman B, Ryan T, Bittner V, Kennedy JW. Comparison of 15-year survival for men and women after initial medical or surgical treatment for coronary artery disease: a CASS registry study. Coronary Artery Surgery Study. Journal of the American College of Cardiology. 1995; 25: 1000-1009.

[7] Sara JD, Widmer RJ, Matsuzawa Y, Lennon RJ, Lerman LO, Lerman A. Prevalence of coronary microvascular dysfunction among patients with chest pain and nonobstructive coronary artery disease. JACC Cardiovascular Interventions. 2016; 8: 1445-1453.

[8] Chaitman BR, Bourassa MG, Davis K, Rogers WJ, Tyras DH, Berger R, et al. Angiographic prevalence of high-risk coronary artery disease in patient subsets (CASS). Circulation. 1981; 64: 360-367. 
[9] Bairey Merz CN, Shaw LJ, Reis SE, Bittner V, Kelsey SF, Olson M, et al. Insights from the NHLBI-Sponsored women's ischemia syndrome evaluation (WISE) study: Part II: gender differences in presentation, diagnosis, and outcome with regard to gender-based pathophysiology of atherosclerosis and macrovascular and microvascular coronary disease. Journal of the American College of Cardiology. 2006; 47: S21-S29.

[10] Dec GW, Fuster V. Idiopathic dilated cardiomyopathy. The New England Journal of Medicine. 1994; 331: 1564-1575.

[11] Codd MB, Sugrue DD, Gersh BJ, Melton LJ. Epidemiology of idiopathic dilated and hypertrophic cardiomyopathy. a population-based study in Olmsted County, Minnesota, 19751984. Circulation. 1989; 80: 564-572.

[12] Coughlin SS, Comstock GW, Baughman KL. Descriptive epidemiology of idiopathic dilated cardiomyopathy in Washington county, Maryland, 1975-1991. Journal of Clinical Epidemiology. 1993; 46: 1003-1008.

[13] Gillum RF. Idiopathic cardiomyopathy in the United States, 1970-1982. American Heart Journal. 1986; 111: 752-755.

[14] Bagger JP, Baandrup U, Rasmussen K, Møller M, Vesterlund T. Cardiomyopathy in western Denmark. British Heart Journal. 1984; 52: 327-331.

[15] Ho CY, Day SM, Ashley EA, Michels M, Pereira AC, Jacoby $\mathrm{D}$, et al. Genotype and lifetime burden of disease in hypertrophic cardiomyopathy: insights from the sarcomeric human cardiomyopathy registry (SHaRe). Circulation. 2018; 138: 1387-1398.

[16] Baldinger SH, Kumar S, Romero J, Fujii A, Epstein LM, Michaud GF, et al. A comparison of women and men undergoing catheter ablation for sustained monomorphic ventricular tachycardia. Journal of Cardiovascular Electrophysiology. 2017; 28: 201-207.

[17] Nakagawa M, Takahashi N, Nobe S, Ichinose M, Ooie T, Yufu F, et al. Gender differences in various types of idiopathic ventricular tachycardia. Journal of Cardiovascular Electrophysiology. 2003; 13: 633-638.

[18] Tanaka Y, Tada H, Ito S, Naito S, Higuchi K, Kumagai K, et al. Gender and age differences in candidates for radiofrequency catheter ablation of idiopathic ventricular arrhythmias. Circulation Journal. 2012; 75: 1585-1591.

[19] Seils DM, Friedman JY, Schulman KA. Sex differences in the referral process for invasive cardiac procedures. Journal of the American Medical Women's Association. 2001; 56: 151-4, 160.

[20] Isensee J, Witt H, Pregla R, Hetzer R, Regitz-Zagrosek V, Noppinger PR. Sexually dimorphic gene expression in the heart of mice and men. Journal of Molecular Medicine. 2009; 86: 61-74.

[21] Gaborit N, Varro A, Le Bouter S, Szuts V, Escande D, Nattel $\mathrm{S}$, et al. Gender-related differences in ion-channel and transporter subunit expression in non-diseased human hearts. Journal of Molecular and Cellular Cardiology. 2010; 49: 639-646.

[22] Fermin DR, Barac A, Lee S, Polster SP, Hannenhalli S, Bergemann TL, et al. Sex and age dimorphism of myocardial gene expression in nonischemic human heart failure. Circulation Cardiovascular Genetics. 2010; 1: 117-125.

[23] Imboden M, Swan H, Denjoy I, Van Langen IM, LatinenForsblom PJ, Napolitano C, et al. Female predominance and transmission distortion in the long-QT syndrome. The New England Journal of Medicine. 2007; 355: 2744-2751.

[24] Trépanier-Boulay V, St-Michel C, Tremblay A, Fiset C. Genderbased differences in cardiac repolarization in mouse ventricle. Circulation Research. 2001; 89: 437-444.

[25] Albert CM, Nam EG, Rimm EB, Jin HW, Hajjar RJ, Hunter DJ, et al. Cardiac sodium channel gene variants and sudden cardiac death in women. Circulation. 2008; 117: 16-23.

[26] Matkovich SJ, Diwan A, Klanke JL, Hammer DJ, Marreez Y, Odley AM, et al. Cardiac-specific ablation of G-protein receptor kinase 2 redefines its roles in heart development and beta-adrenergic signaling. Circulation Research. 2006; 99: 996 1003.

[27] Li M, Parker BL, Pearson E, Hunter B, Cao J, Koay YC, et al. Core functional nodes and sex-specific pathways in human ischaemic and dilated cardiomyopathy. Nature Communications. 2020; 11: 2843.

[28] Heidecker B, Lamirault G, Kasper EK, Wittstein IS, Champion $\mathrm{HC}$, Breton E, et al. The gene expression profile of patients with new-onset heart failure reveals important gender-specific differences. European Heart Journal. 2011; 31: 1188-1196.

[29] Meng H, Zhang Y, An S, Chen Y. Annexin a3 gene silencing promotes myocardial cell repair through activation of the PI3KAkt signaling pathway in rats with acute myocardial infarction. Journal of Cellular Physiology. 2019; 234: 10535-10546.

[30] Li XS, Obeid S, Klingenberg R, Gencer B, Mach F, Räber L, et al. Gut microbiota-dependent trimethylamine $\mathrm{N}$-oxide in acute coronary syndromes: a prognostic marker for incident cardiovascular events beyond traditional risk factors. European Heart Journal. 2018; 38: 814-824.

[31] Casin KM, Fallica J, Mackowski N, Veenema RJ, Chan A, St Paul A, et al. S-Nitrosoglutathione Reductase Is Essential for Protecting the Female Heart From Ischemia-Reperfusion Injury. Circulation Research. 2018; 123: 1232-1243.

[32] Stumpf WE, Sar M, Aumüller G. The heart: a target organ for estradiol. Science. 1977; 196: 319-321.

[33] Hara M, Danilo P, Rosen MR. Effects of gonadal steroids on ventricular repolarization and on the response to E4031. The Journal of Pharmacology and Experimental Therapeutics. 1998; 285: 1068-1072.

[34] Chen YJ, Lee SH, Hsieh MH, Hsiao CJ, Yu WC, Chiou CW, et $a l$. Effects of 17beta-estradiol on tachycardia-induced changes of atrial refractoriness and cisapride-induced ventricular arrhythmia. Journal of Cardiovascular Electrophysiology. 1999; 10: $587-598$.

[35] James AF, Arberry LA, Hancox JC. Gender-related differences in ventricular myocyte repolarization in the guinea pig. Basic Research in Cardiology. 2004; 99: 183-192.

[36] Dogan M, Yiginer O, Uz O, Kucuk U, Degirmencioglu G, Isilak Z, et al. The effects of female sex hormones on ventricular premature beats and repolarization parameters in physiological menstrual cycle. Pacing and Clinical Electrophysiology. 2017; 39: 418-426.

[37] Brodsky MA, Sato DA, Oster PD, Schmidt PL, Chesnie BM, Henry WL. Paroxysmal ventricular tachycardia with syncope during pregnancy. The American Journal of Cardiology. 1986; 58: 563-564.

[38] McMillan TM, Bellet S. Ventricular paroxysmal tachycardia: report of a case in a pregnant girl of sixteen years with an apparently normal heart. American Heart Journal. 1931; 7: 70-78.

[39] Brodsky M, Doria R, Allen B, Sato D, Thomas G, Sada M. Newonset ventricular tachycardia during pregnancy. American Heart Journal. 1992; 123: 933-941.

[40] Natale A, Davidson T, Geiger MJ, Newby K. Implantable cardioverter-defibrillators and pregnancy: a safe combination? Circulation. 1997; 96: 2808-2812.

[41] Marchlinski FE, Deely MP, Zado ES. Sex-specific triggers for right ventricular outflow tract tachycardia. American Heart Journal. 2000; 139: 1009-1013.

[42] Hu X, Jiang H, Xu C, Zhou X, Cui B, Lu Z. Relationship between sex hormones and idiopathic outflow tract ventricular arrhythmias in adult male patients. Translational Research. 2009; 154: $265-268$.

[43] Cano O, Hutchinson M, Lin D, Garcia F, Zado E, Bala R, et al. Electroanatomic substrate and ablation outcome for suspected epicardial ventricular tachycardia in left ventricular nonischemic cardiomyopathy. Journal of the American College of Cardiol- 
ogy. 2009; 54: 799-808.

[44] Piers SRD, Dyrda K, Tao Q, Zeppenfeld K. Bipolar ablation of ventricular tachycardia in a patient after atrial switch operation for dextro-transposition of the great arteries. Circulation. Arrhythmia and Electrophysiology. 2012; 5: e38-e40.

[45] Buxton AE, Hafley GE, Lehmann MH, Gold M, O'Toole M, Tang A, et al. Prediction of sustained ventricular tachycardia inducible by programmed stimulation in patients with coronary artery disease. Utility of clinical variables. Circulation. 1999; 99 : $1843-1850$

[46] Kuo L, Shirai Y, Muser D, Liang JJ, Castro SA, Santangeli P, et al. Comparison of the arrhythmogenic substrate between men and women with nonischemic cardiomyopathy. Heart Rhythm. 2019; 16: 1414-1420.

[47] Yang S, Mlček M, Kittnar O. Gender differences in electrophysiological characteristics of idiopathic ventricular tachycardia originating from right ventricular outflow tract. Physiological Research. 2015; 63: S451-S458.

[48] Lin C, Chung F, Lin Y, Chang S, Lo L, Hu Y, et al. Gender differences in patients with arrhythmogenic right ventricular dysplasia/cardiomyopathy: Clinical manifestations, electrophysiological properties, substrate characteristics, and prognosis of radiofrequency catheter ablation. International Journal of Cardiology. 2017; 227: 930-937.

[49] Surget E, Cheniti G, Ramirez FD, Leenhardt A, Nogami A, Gandjbakhch E, et al. Sex differences in the origin of Purkinje ectopy-initiated idiopathic ventricular fibrillation. Heart Rhythm. 2021; 18: 1647-1654.

[50] Cassidy DM, Vassallo JA, Marchlinski FE, Buxton AE, Untereker WJ, Josephson ME. Endocardial mapping in humans in sinus rhythm with normal left ventricles: activation patterns and characteristics of electrograms. Circulation. 1984; 70: 37-42.

[51] Sramko M, Abdel-Kafi S, van der Geest RJ, de Riva M, Glashan $\mathrm{CA}, \mathrm{Lamb} \mathrm{HJ}$, et al. New adjusted cutoffs for "normal" endocardial voltages in patients with post-infarct lv remodeling. JACC Clinical Electrophysiology. 2019; 5: 1115-1126.

[52] Hutchinson MD, Gerstenfeld EP, Desjardins B, Bala R, Riley MP, Garcia FC, et al. Endocardial unipolar voltage mapping to detect epicardial ventricular tachycardia substrate in patients with nonischemic left ventricular cardiomyopathy. Circulation. Arrhythmia and Electrophysiology. 2011; 4: 49-55.

[53] Reddy VY, Reynolds MR, Neuzil P, Richardson AW, Taborsky $\mathrm{M}$, Jongnarangsin $\mathrm{K}$, et al. Prophylactic catheter ablation for the prevention of defibrillator therapy. The New England Journal of Medicine. 2008; 357: 2657-2665.

[54] Kuck K, Schaumann A, Eckardt L, Willems S, Ventura R, Delacrétaz E, et al. Catheter ablation of stable ventricular tachycardia before defibrillator implantation in patients with coronary heart disease (VTACH): a multicentre randomised controlled trial. Lancet. 2010; 375: 31-40.

[55] Kuck K, Tilz RR, Deneke T, Hoffmann BA, Ventura R, Hansen PS, et al. Impact of substrate modification by catheter ablation on implantable cardioverter-defibrillator interventions in patients with unstable ventricular arrhythmias and coronary artery disease: results from the multicenter randomized controlled SMS (Substrate Modification Study). Circulation Arrhythmia and Electrophysiology. 2017; 10: e004422.

[56] Sapp JL, Wells GA, Parkash R, Stevenson WG, Blier L, Sarrazin $\mathrm{JF}$, et al. Ventricular tachycardia ablation versus escalation of antiarrhythmic drugs. The New England Journal of Medicine. 2016; 375: 111-121.

[57] Willems S, Tilz RR, Steven D, Kääb S, Wegscheider K, Gellér
$\mathrm{L}$, et al. Preventive or deferred ablation of ventricular tachycardia in patients with ischemic cardiomyopathy and implantable defibrillator (BERLIN VT): a multicenter randomized trial. Circulation 2020; 141:1057-1067.

[58] Vitale C, Fini M, Spoletini I, Lainscak M, Seferovic P, Rosano GM. Under-representation of elderly and women in clinical trials. International Journal of Cardiology. 2017; 232: 216-221.

[59] Divoky L, Maran A, Ramu B. Gender differences in ischemic cardiomyopathy. Current Atherosclerosis Reports. 2019; 20: 50

[60] Marchlinski FE, Callans DJ, Gottlieb CD, Zado E. Linear ablation lesions for control of unmappable ventricular tachycardia in patients with ischemic and nonischemic cardiomyopathy. Circulation. 2000; 101: 1288-1296.

[61] Berruezo A, Fernández-Armenta J, Mont L, Zeljko H, Andreu D, Herczku C, et al. Combined endocardial and epicardial catheter ablation in arrhythmogenic right ventricular dysplasia incorporating scar dechanneling technique. Circulation. Arrhythmia and Electrophysiology. 2012; 5: 111-121.

[62] Di Biase L, Santangeli P, Burkhardt DJ, Bai R, Mohanty P, Carbucicchio C, et al. Endo-epicardial homogenization of the scar versus limited substrate ablation for the treatment of electrical storms in patients with ischemic cardiomyopathy. Journal of the American College of Cardiology. 2012; 60: 132-141.

[63] Tzou WS, Frankel DS, Hegeman T, Supple GE, Garcia FC, Santangeli $\mathrm{P}$, et al. Core isolation of critical arrhythmia elements for treatment of multiple scar-based ventricular tachycardias. Circulation. Arrhythmia and Electrophysiology. 2015; 8: 353-361.

[64] Jaïs P, Maury P, Khairy P, Sacher F, Nault I, Komatsu Y, et al. Elimination of local abnormal ventricular activities: a new end point for substrate modification in patients with scar-related ventricular tachycardia. Circulation. 2012; 125: 2184-2196.

[65] Arenal A, Glez-Torrecilla E, Ortiz M, Villacastín J, FdezPortales J, Sousa E, et al. Ablation of electrograms with an isolated, delayed component as treatment of unmappable monomorphic ventricular tachycardias in patients with structural heart disease. Journal of the American College of Cardiology. 2003; 41: 81-92.

[66] Vergara P, Trevisi N, Ricco A, Petracca F, Baratto F, Cireddu $\mathrm{M}$, et al. Late potentials abolition as an additional technique for reduction of arrhythmia recurrence in scar related ventricular tachycardia ablation. Journal of Cardiovascular Electrophysiology. 2012; 23: 621-627.

[67] Okubo K, Gigli L, Trevisi N, Foppoli L, Radinovic A, Bisceglia $\mathrm{C}$, et al. Long-Term Outcome after Ventricular Tachycardia Ablation in Nonischemic Cardiomyopathy. Circulation: Arrhythmia and Electrophysiology. 2020; 13: e008307.

[68] Aziz Z, Shatz D, Raiman M, Upadhyay GA, Beaser AD, Besser $\mathrm{SA}$, et al. Targeted ablation of ventricular tachycardia guided by wavefront discontinuities during sinus rhythm. Circulation. 2019; 140: 1383-1397.

[69] Frankel DS, Tung R, Santangeli P, Tzou WS, Vaseghi M, Di Biase $\mathrm{L}$, et al. Sex and catheter ablation for ventricular tachycardia: an international ventricular tachycardia ablation center collaborative group study. JAMA Cardiology. 2018; 1: 938-944.

[70] Hosseini SM, Rozen G, Saleh A, Vaid J, Biton Y, Moazzami K, et al. Catheter ablation for cardiac arrhythmias: utilization and in-hospital complications, 2000 to 2013. Journal of American College of Cardiology. 2019; 3: 1240-1248.

[71] Santangeli P, Muser D, Zado ES, Magnani S, Khetpal S, Hutchinson MD, et al. Acute hemodynamic decompensation during catheter ablation of scar-related ventricular tachycardia. Circulation. 2015; 8: 68-75. 